\title{
Phylogenic and antagonistic characteristics of novel Bacillus cereus isolates against desert locust, Schistocerca gregaria Forskal (Orthoptera: Acrididae)
}

\author{
Mohamed Reda ${ }^{1 *}$ (D), Tamer Abdallah Mashtoly², Mohamed El-Said El-Zemaity ${ }^{2}$, Assem Abolmaaty ${ }^{3}$ \\ and Gamal Mohamed Abdelatef ${ }^{1}$
}

\begin{abstract}
Thirty bacterial strains were successfully isolated from dead/diseased nymphs of the desert locust Schistocerca gregaria Forskal (Orthoptera: Acrididae) occurred in rearing cages at Locust and Grasshoppers Research Department, Plant Protection Research Institute, Agricultural Research Center, Dokki, Giza, Egypt. Among them, two isolates, DL3 and DL4, showed a high biocidal activity against locust at preliminary bracketing bioassay. Molecular identification of the two bacterial isolates was carried out by sequencing the $16 \mathrm{~S}$ rRNA gene and nucleotide blast of international GenBank, and the results showed that DL3 isolate was Bacillus cereus (KY630646) and DL4 isolate was Bacillus cereus (KY630647) with a 100\% similarity with Bacillus cereus strain SZAN-2 (GU222440) and Bacillus cereus strain KPRR3 (KY556439), respectively. The insecticidal activity of both isolates against locust nymphs using leaf dipping and per os techniques proved that DL4 isolate was more efficient than DL3 and both of them have the potential to be successful biocidal agents to control desert locust.
\end{abstract}

Keywords: Schistocerca gregaria, Biological control, Entomopathogenic bacteria, 16S rRNA genes sequencing

\section{Background}

Locusts are known as one of the most worldwide destructive pests, causing severe agriculture disaster due to the nature of damage caused by locust swarm (Lecoq 2001). Conventional control of locust is mainly relied on chemical insecticides which are effective in suppressing the locust swarm. However, lots of safety concerns were raised about agrochemical practices for controlling locusts. Also, exploring alternative biocontrol agents has become inevitability needed for locust management (Lomer et al. 2001). Biological control using antagonists has proven to be one of the most promising alternatives, either alone or as part of an integrated pest management policy, to reduce pesticide use (Bacon and Hinton 2002; Spadaro and Gullino 2004). In this respect, the $16 \mathrm{~S}$ rRNA gene sequence

\footnotetext{
* Correspondence: m.reda@agr.asu.edu.eg

'Department of Locust and Grasshoppers Research, Plant Protection Research Institute, Agricultural Research Center, Dokki, Giza, Cairo 12311, Egypt

Full list of author information is available at the end of the article
}

analysis is an efficient method for specific identification of antagonistic bacteria on the genus level (Woese et al. 1985 and Clarridge 2004). Moreover, it clearly distinguishes the phylogenetic analytical differences between the newly identified isolates and other related strains (Woese et al. 1985). Bacterial insecticides have been developed for the control of lepidopteran, dipteran, and coleopteran pests. Some articles indicated that Bacillus cereus has been used successfully as a microbial control agent against the grubs of Amphimallon solstitiale, Melolontha melolontha, Anomala dimidiate, and Holotrichia seticollis (Sezen et al. 2005; Selvakumar et al. 2007 and Sushil et al. 2008). PCR primers were designed for the identification of 23 isolates via genotyping genes of phosphatidylcholine-specific phospholipase $\mathrm{C}$, phosphatidylinositol-specific phospholipase $\mathrm{C}$, immune inhibitor $\mathrm{A}$, and vegetative insecticidal protein 3A (Guttmann and Ellar 2000).

The objective of the present work was to evaluate the antagonistic characteristics of two bacterial isolates against nymphal stage of the desert locust. In addition, 
the two isolates were identified, using 16S rRNA gene sequence analysis.

\section{Methods}

Source of used insects

Nymphs and adults of desert locust Schistocerca gregaria, reared in locust laboratory at Department of Locust and Grasshoppers Research, Plant Protection Research Institute, Agricultural Research Center, Dokki, Giza, Egypt, were examined daily for separation of the dead from the infected ones (presented certain symptoms that suggest bacterial infection; those become flaccid, lethargic, reddish or brownish, and stop feeding). Separated insects were brought in sterilized tubes to Microbiological Resources Center (MIRCEN) at the Faculty of Agriculture, Ain Shams University, Cairo, Egypt, for identifying the microbial causative of the symptoms.

\section{Isolation of bacteria from infected insects}

Dead and infected nymphs and adults were placed separately in sterile tubes and transferred to the microbiology lab for bacterial isolation. Isolation was carried out through three procedures: "body surface, internal swap, and dead locust paste." Body surface of dead/infected locusts was ascetically swapped by sterilized swap into $10 \mathrm{ml}$ of sterilized distilled water, and then streaking was conducted on nutrient agar plates. Internal swap was also taken from midgut and the cavity of dead/infected locusts into $10 \mathrm{ml}$ of sterilized distilled water and then streaking was performed on nutrient agar plates. Dead locust paste was ascetically swapped and directly streaked on nutrient agar plates. All the plates were incubated at $28^{\circ} \mathrm{C} / 72 \mathrm{~h}$. Distinguished isolates were picked up based on colony color and its morphological characteristics. Streaking was repeated three times on nutrient agar plates every $72 \mathrm{~h}$ for each selected colony. Isolates were examined by microscopic observation for parasporal inclusions and gram staining. All purified isolates were subjected to bioassay.

\section{Screening for bioactive bacterial isolates against locust}

All isolates were grown in nutrient broth overnight at $30{ }^{\circ} \mathrm{C} / 150 \mathrm{rpm}$ agitation and then centrifuged at $4000 \mathrm{rpm}$ for $15 \mathrm{~min}$ at $4{ }^{\circ} \mathrm{C}$ to collect cell (pellets). Cell densities of each isolate were adjusted and mixed in a $50 \mathrm{ml}$ beaker (Tables 1 and 2). Egyptian clover fresh sticks and leaves were used as a solo feed after dipping in each bacterial suspension individually for $3 \mathrm{~min}$. Sticks and leaves were allowed to dry for $10 \mathrm{~min}$ under the ambient temperature. Each bacterial strain was introduced to five $4^{\text {th }}$ nymphal instar of locust using the treated sticks and leaves. It was then placed in individual plastic boxes (30-cm-long and $18 \mathrm{~cm}$ in width). Daily examination was performed for 10 days, and mortality percentage was recorded. Out of 30 bacterial isolates,
Table 1 Preparation of different cell concentrations (CFU/ml) of the two selected isolates used in leaf dipping technique

\begin{tabular}{llllll}
\hline Strains & $\begin{array}{l}\text { Stock } \\
\text { solution } \\
\text { (CFU/ml) }\end{array}$ & \multicolumn{4}{l}{ Dilutions $(\mathrm{CFU} / \mathrm{ml})$} \\
\cline { 3 - 6 } & & 2 & 3 & 4 \\
\hline DL3 & $539 \times 10^{6}$ & $269 \times 10^{6}$ & $134 \times 10^{6}$ & $67 \times 10^{6}$ & $33 \times 10^{6}$ \\
DL4 & $23 \times 10^{6}$ & $11.5 \times 10^{6}$ & $5.7 \times 10^{6}$ & $2.8 \times 10^{6}$ & $1.4 \times 10^{6}$ \\
\hline
\end{tabular}

two proved the potential antagonistic activity against locust. The selected isolates and the ones that showed potential antagonistic activities against locust were subjected to bioassay and identification using $16 \mathrm{~S}$ rRNA gene sequencing.

\section{Preparation of bacterial stock solution}

A culture from each selected isolate at a fixed cell concentration of colony-forming units (CFUs) and graduate dilutions was prepared according to Mashtoly et al. (2010 and 2011). One hundred milliliters of nutrient broth media was inoculated by each isolate and incubated overnight in $250 \mathrm{ml}$ baffled flasks at $30{ }^{\circ} \mathrm{C}$ with a rotary agitation $(150 \mathrm{rpm})$. Exponentially growing cells $\left(\sim 1 \times 10^{6}\right.$ cells $\left./ \mathrm{ml}\right)$ were harvested by centrifuging broth culture at $4000 \mathrm{rpm} /$ $15 \mathrm{~min} / 4{ }^{\circ} \mathrm{C}$. The supernatants were disposed off, and pellets were washed twice by suspending cells in $40 \mathrm{ml}$ phosphate buffer saline (PBS). Pellets were resuspended in $40 \mathrm{ml} \mathrm{PBS}$, and absorbance of cell suspension was measured at $600 \mathrm{~nm}$ using an Eppendorf bio photometer $8.5 \mathrm{~mm}$ light center. A plate count of each isolate cell suspension was conducted in nutrient agar at $30{ }^{\circ} \mathrm{C}$ for $48 \mathrm{~h}$ with serial dilutions of cell suspension. All measures were performed in triplicate, and the mean values were used to measure colony-forming units that correspond to absorption at $600 \mathrm{~nm}$. Bacterial concentrations used in bioassays were expressed as colony-forming units per milliliter.

\section{Morphological analysis}

Each pure culture of the two selected isolates was subjected to Gram stain test. Parasporal and inclusion bodies test was done using a light microscope to detect for spores and crystals for each individual effective isolate. One hundred milliliters of nutrient broth media was inoculated by one loop of each isolate and incubated at $30{ }^{\circ} \mathrm{C}$ with a rotary agitation of $150 \mathrm{rpm}$ for 4 days. Fifty microliters of each cell suspension were placed on glass

Table 2 Preparation of different cell concentrations (CFU/ml) of the two selected isolates used in per os technique

\begin{tabular}{llllll}
\hline Strains & $\begin{array}{l}\text { Stock } \\
\text { solution } \\
(\text { CFU/ml) }\end{array}$ & \multicolumn{4}{l}{ Dilutions $(\mathrm{CFU} / \mathrm{ml})$} \\
\cline { 3 - 6 } & 1 & 2 & 3 & 4 \\
\hline DL3 & $1078 \times 10^{6}$ & $539 \times 10^{6}$ & $270 \times 10^{6}$ & $135 \times 10^{6}$ & $67 \times 10^{6}$ \\
DL4 & $467 \times 10^{6}$ & $233 \times 10^{6}$ & $117 \times 10^{6}$ & $58 \times 10^{6}$ & $29 \times 10^{6}$ \\
\hline
\end{tabular}


slide, covered, and examined by the $\times 100$ lens of the light microscope.

\section{Bioassay}

A leaf dipping and per os bioassay techniques were used to evaluate the susceptibility of $4^{\text {th }}$ nymphal instar of desert locust to the selected bacterial isolates.

\section{Leaf dipping technique}

Stock solution of the selected isolates was prepared, and colony-forming units per milliliter and four graduate dilutions were used as shown in Table 1. Calculation and use of these concentrations were suggested by preliminary bracketing bioassays (unpublished data). Adequate fresh sticks and leaves of clover were immersed in each bacterial concentration and water, as control treatment, for $3 \mathrm{~min}$ with gentle agitation, ensuring that the entire surface was immersed equally in suspended insecticides, and then allowed to dry at ambient temperature for $10 \mathrm{~min}$. Treated sticks and leaves of the same isolate were introduced to three sets (replicates) of ten 4th instar nymph individuals. Nymphs in each replicate were placed in individual small wooden frame (30-cm-long, 18-cm-width, and 20-cm-height) with wire gauze in front and top for easy usage. Replicates were kept under the same rearing laboratory conditions. Control trial followed the same procedure, except using water instead of the bacterial suspension. Sticks and leaves were dipped in autoclaved distilled water and then allowed to dry, then introduced to 30 nymphs. Daily examination of treated and control insects was recorded to determine mortality rates which were subjected to statistical analysis.

\section{Per os technique}

Stock solutions of the two selected isolates were prepared, and cell concentration $(\mathrm{CFU} / \mathrm{ml})$ of each isolate was calculated. Serial dilutions of each were prepared and used per os as shown in Table 2. These concentrations were used after preliminary bioassays. All dilutions were expressed as colony-forming units per milliliter and administered per os via $1 \mathrm{~cm}$ Hamilton syringe equipped with 27-gauge needle to $4^{\text {th }}$ instar nymph of $S$. gregaria. Per os treatment was done using different doses of cell concentrations in $0.2 \mathrm{ml}(200 \mu \mathrm{l})$ per individual insect and subsequently for other strain. Five nymphs 4th instar were treated, and each of them was used as an individual replicate. Daily examination of treated and control trials was recorded. Mortality rates were recorded and subjected to statistical analysis.

Obtained mortalities of each of the two experiments were pooled together then subjected to probit analysis using the PROC PROBIT Statistical Analysis program Version 9.4. The average of control mortality (\%) was 7.5\%. Toxicity regression lines were drawn using Sigma Plot 12 . When comparing $\mathrm{LC}_{50}$ values, a failure of $95 \%$ confidence limits to overlap was used as a measure to determine significant differences between treatments. In all cases, the likelihood ratio (L.R.) chi-square goodness-of-fit values indicated that the data adequately conformed to the probit model.

\section{Molecular identification of the bacterial isolates using $16 \mathrm{~S}$ rRNA sequencing: 16S rRNA genes amplification}

Extraction of genomic DNA was conducted, using Promega Wizard ${ }^{\circledR}$ Genomic DNA Purification Kit. Amplification of 16S rRNA gene. One set of universal Primers 27F (5' - AGA GTT TGA TCM TGG CTC AG -3'); 1492R (5' - TAC GGY TAC CTT GTT ACG ACT T -3') were used to amplify and sequence $500 \mathrm{bp}$ of target $16 \mathrm{~S}$ rRNA. Primers used for sequencing were 518F (5' - CCA GCA GCC GCG GTA ATA CG-3'); 800R (5'-TAC CAG GGT ATC TAA TCC-3'). The primer was synthesized and purchased from integrated DNA Technologies, Inc. Amplification was conducted using PTC-100TM Programmable thermal controller (MJ Research, Inc.) with a PCR mixture of $45 \mu$ Platinum PCR Super Mix 1.1X (Invitrogen Crop.), $1.0 \mu \mathrm{l}$ of each forward and reverse primer, and three of target DNA in a final volume of $50 \mu \mathrm{l}$. The anti-Taq polymerase DNA antibody, $\mathrm{Mg}++\mathrm{dNTPs}$, and recombinant Taq DNA polymerase were adjusted at concentrations sufficient to allow amplification during PCR process. The cycling conditions consisted of initial denaturation at $94{ }^{\circ} \mathrm{C}$ for $45 \mathrm{~s}$, annealing at $55^{\circ} \mathrm{C}$ for $60 \mathrm{~s}$, and extension at $72{ }^{\circ} \mathrm{C}$ for $3 \mathrm{~min}$ with a final extension at $72{ }^{\circ} \mathrm{C}$ for $10 \mathrm{~min}$. Blanks were routinely contained all components of the PCR reaction mixture, except the DNA template. PCR products were subjected to $2 \%$ agarose gels with $5 \mu$ l of SYBR ${ }^{\oplus}$ safe DNA gel stain (Invitrogen Corp.) in electrophoresis running buffer (0.2) M Tris base, $0.1 \mathrm{M}$ Sodium acetate, 0.01 M NA2.EDTA, at PH 7.8). Digital images were obtained using a BIO-RAD Universal Hood \| ChemiDocTM CheXRS molecular imager and Mitsubishi P93 printer.

\section{Gene sequencing and phylogenetic analysis}

Amplified 16S rRNA genes were purified using QIA quick PCR Purification Kit (Qiagen), following the manufacturer's instructions via spin-column technology with the selective binding properties of a uniquely designed silica membrane. Binding buffer (PB), washing buffer $(\mathrm{PE})$, and elution buffer (EB) provided were optimized for efficient recovery of DNA. PCR products were also purified using Montage PCR Clean up kit (Millipore). Elution efficiency was strongly dependent on salt concentration and $\mathrm{pH}$ values of the elution buffer. Contrary to adsorption, elution was the most efficient under basic conditions with a low salt concentration. DNA was eluted with $30 \mu \mathrm{l}$, applied to the column center, of buffer EB (10 mM Tris. C1, Ph 8.5) or Ultra-pure DNAse/ RNAse free water and then the column was incubated 
for $1 \mathrm{~min}$ at room temperature; the maximum elution efficiency was achieved between $\mathrm{pH} 7.0$ and 8.5.The sequencing of the purified PCR products of approximately 1400 bp was carried out in the Macrogen sequencing service. Sequencing was performed using Big Dye terminator cycle sequencing kit (Applied BioSystems, USA). 16S rRNA genes sequences were resolved on an Applied BiosyStems model 3730XL automated DNA sequencing system (Applied BioSystems, USA) and analyzed by Sequence Scanner Version: $1.0^{(\mathrm{c})}$ copyright Applied Biosystem. 2005. NCBI database at (https://blast.ncbi.nlm.nih.gov) was used to compare 16S rRNA gene sequences of the present isolates with other 16S rRNA sequences (Altschul et al, 1990). Multiple sequences were aligned using the CLUSTAL W program against corresponding nucleotide sequences (Thompson et al. 1994). This would display the closest matches to respective 16S rDNA sequences for identifying known species. Sequence analysis and Phylogenetic tree construction were then conducted using the Molecular Evolutionary Genetics Analysis (MEGA) software version 7. Partial 16S rRNA gene sequences of isolate DL3 and DL4 were compared with other 16S rRNA sequences of valid microbial strains published in NCBI database at (https://blast.ncbi.nlm.nih.gov).

\section{Results and discussion}

\section{Isolation and screening for bioactive isolates against} desert locust

Isolation of the bacteria from the infected locusts resulted in 30 isolates (data not shown), of which the two, DL3 and DL4, were selected based on their bioactivity against the pest. These two isolates were used in the following experiments.

\section{Bioassays of the two tested bacterial strains against desert locust}

The morphological examination of all purified isolates via light microscope emphasized that there were two new Gram-positive spore-forming bacteria DL3 and DL4. However, none of them had the ability to produce inclusion bodies or crystal protein. The pathogenicity of all purified isolates revealed that DL3 and DL4 were the most effective isolates, in preliminary bracketing, having the highest relative potency in antagonistic impacts on biochemical processes in the midgut of desert locust. Susceptibility of 4th nymphal instar of desert locust to DL3 and DL4 isolates, using leaf dipping technique, showed that their $\mathrm{LC}_{50}$ values after $48 \mathrm{~h}$ were $73 \times 10^{6}$ and $2 \times 10^{6}$ for DL3 and DL4, respectively. Data in Table 3 suggest that DL4 was more virulent than DL3. Failure of overlap at 95\% confidence limits was considered as evidence for significant differences at the $\mathrm{LC}_{50}$ level. The toxicity index values calculated from the leaf-dip bioassay demonstrated the relative toxicity between the most efficient isolate (DL4) as standard and the other isolate DL3, whereas the efficiency of DL4 was approximately 37-fold the efficacy of DL3 (Table 3). On the other hand, data in per os bioassay presented in Table 4 revealed a similar trend of efficiency, whereas DL4 had toxicity 4.6-fold that of DL3according to calculated toxicity index. There was a significant difference between the two isolates in leaf-dip bioassay, whereas fiducial limits at $95 \%$ of $\mathrm{LC}_{50}$ 's did not show overlap. However, there was no significant difference between the two isolates showed in per os bioassay. Desert locust control mainly relies on chemical insecticide; Dieldrin was the most effective and economical control insecticide because of its long persistence. Providing an overview of the pathogens that affect acridids, those include bacteria, viruses, nematodes, microsporidia, and fungi. The first microbial control agent developed for acridids control was Nosema locustae Canning, but a demand for more rapid kill led to the development of fungi capable of penetrating insect cuticle (Goettel and Jaronski 1997). Johnson (1997) stated that the majority of virulent isolates found so far belong to Metarhizium acridum. In the field, the use of Metarhizium has a relatively slow and variable speed of kill, which may create practical problems for its use (Lomer et al. 2001); therefore, the tested isolates in the present study may become promising entomopathogens agents for desert locust control for their rapid speed of kill. An increasing awareness of the negative environmental impact of organochlorine pesticides has led to restriction of their use to certain limited public health applications. Organophosphate, carbamate, and pyrethroid pesticides replaced dieldrin for locust and grasshopper control (Lomer et al. 2001). The substitute organophosphate pesticides, such as fenitrothion and malathion, had shorter environmental persistence and were often repeatedly applied as blanket treatments over large areas. Ironically, such treatments may cause greater environmental hazards than the organochlorine treatments. Most of the

Table 3 Toxicity values of DL3 and DL4 isolates to 4th nymphal instar of S. gregaria using leaf dipping technique

\begin{tabular}{lllllll}
\hline Isolate & $N$ & Slope (SE) & $\mathrm{LC}_{50}{ }^{\mathrm{ab}}$ & $X^{2}(\mathrm{df})^{\mathrm{c}}$ & $95 \% \mathrm{FL}$ & Toxicity index $^{\mathrm{d}}$ \\
\hline DL3 & 180 & $2.44(0.37)$ & $73 \times 10^{6} \mathrm{~b}$ & $3.07(3)$ & $55 \times 10^{6}-92 \times 10^{6}$ & 2.7 \\
DL4 & 180 & $1.9(0.33)$ & $2 \times 10^{6} \mathrm{a}$ & $3.6(3)$ & $1 \times 10^{6}-3 \times 10^{6}$ & 100 \\
\hline
\end{tabular}

$N$ refers to total number of insects in treatment

${ }^{\mathrm{a}} \mathrm{LC}_{50}$ 's reported in CFUs

${ }^{b} C_{50}$ 's followed by the same letter are not significantly different based on overlap of their $95 \%$ Fiducial limits $(P<0.05)$

'L.R. chi-square goodness-of-fit values. Tabular values at $P=0.05$ for $3 \mathrm{df}=7.81$

${ }^{\mathrm{d}}$ Toxicity index (Sun 1950) $=\left(\mathrm{LC}_{50}\right.$ of the most efficient compound (as standard) $/ L C_{50}$ of the other tested compound $) \times 100$ 
Table 4 Toxicity values of DL3 and DL4 isolates to $4^{\text {th }}$ instar nymphs of S. gregaria using per os technique

\begin{tabular}{lllllll}
\hline Isolate & $N$ & Slope (SE) & $\mathrm{LC}_{50}{ }^{\mathrm{a}}$, b & $x^{2}(\mathrm{df})^{\mathrm{c}}$ & $95 \% \mathrm{FL}$ & Toxicity index $^{\mathrm{d}}$ \\
\hline DL3 & 30 & $2.18(0.8)$ & $181 \times 10^{6} \mathrm{a}$ & $0.62(3)$ & $60 \times 10^{6}-374 \times 10^{6}$ & 21.5 \\
DL4 & 30 & $2.3(0.7)$ & $39 \times 10^{6} \mathrm{a}$ & $0.7(4)$ & $14 \times 10^{6}-74 \times 10^{6}$ & 100 \\
\hline
\end{tabular}

$N$ Refers to total number of insects in treatment

${ }^{\mathrm{a}} \mathrm{LC}_{50}$ 's reported in CFUs

${ }^{b}$ LC 50 's followed by the same letter are not significantly different based on overlap of their $95 \%$ Fiducial limits $(P<0.05)$

C L.R. chi-square goodness-of-fit values. Tabular values at $P=0.05$ for $3 \mathrm{df}=7.81,4 \mathrm{df}=9.49$

${ }^{\mathrm{d}}$ Toxicity index (Sun 1950) $=\left(\mathrm{LC}_{50}\right.$ of the most efficient compound (as standard) $/ \mathrm{LC} \mathrm{C}_{50}$ of the other tested compound $) \times 100$

modern control operations rely on safer organophosphates such as fenitrothion; carbamates such as bendiocarb; pyrethroid such as deltamethrin and lambda-cyhalothrin, Fipronil; and insect growth regulators such as dimilin and triflumeron.

\section{Molecular identification of bacterial isolates using $16 \mathrm{~S}$ rRNA sequencing technique}

PCR amplification of 16S rRNA genes (gamma region) was performed for genotyping identification of isolates DL3 and DL4. Digital images of agarose gel were captured by UV transilluminator (Bio-Rad Laboratories, Hercules, CA) and confirmed the amplification of 500-bp fragments of $16 \mathrm{~S}$ rRNA gene (Fig. 1).

$16 \mathrm{~S}$ rRNA genes sequence analysis and phylogenetic tree Universal PCR offers a great advantage for the identification of actinomycetes (Provost et al. 1997). Amplicons resulting from primer pairs were selected for the identification of isolates DL3 and DL4. The genus Bacillus was found to be the predominant identified bacteria when sequences were blasted against nucleotide database using a nucleotide query algorithm. The partial $16 \mathrm{~S}$ rRNA gene sequence is already deposited in the GenBank under the accession number KY630646 and KY630647, respectively.

CCGCACAAGCGGTGGAGCATGTGGTTTAATTCGA AGCAACGCGAAGAACCTTACCAGGTCTTGACATCC TCTGACAACCCTAGAGATAGGGCTTCTCCTTCGGG AGCAGAGTGACAGGTGGTGCATGGTTGTCGTCAGC TCGTGTCGTGAGATGTTGGGTTAAGTCCCGCAACG AGCGCAACCCTTGATCTTAGTTGCCATCATTAAGT TGGGCACTCTAAGGTGACTGCCGGTGACAAACCGG AGGAAGGTGGGGATGACGTCAAATCATCATGCCCC
TTATGACCTGGGCTACACACGTGCTACAATGGACG GTACAAAGAGCTGCAAGACCGCGAGGTGGAGCTAA TCTCATAAAACCGTTCTCAGTTCGGATTGTAGGCT GCAACTCGCCTACATGAAGCTGGAATCGCTAGTAA TCGCGGATCAGCATGCCGCGGTGAATACGTTCCCG GGCCTTGTACACACCGCCCGTCACACCACGAGAGT $\mathrm{T}$ and GAGTGATGAAGGCTTTCGGGTCGTAAAACTC TGTTGTTAGGGAAGAACAAGTGCTAGTTGAATA AGCTGGCACCTTGACGGTACCTAACCAGAAAGCCA CGGCTAACTACGTGCCAGCAGCCGCGGTAATACGT AGGTGGCAAGCGTTATCCGGAATTATTGGGCGTAA AGCGCGCGCAGGTGGTTTCTTAAGTCTGATGTGAA AGCCCACGGCTCAACCGTGGAGGGTCATTGGAAAC TGGGAGACTTGAGTGCAGAAGAGGAAAGTG GAATTCCATGTGTAGCGGTGAAATGCGTAGAGATA TGGAGGAACACCAGTGGCGAAGGCGACTTTCTGGT CTGTAACTGACACTGAGGCGCGAAAGCGTGGGGAG CAAACAGGATTAGATACCCTGGTAGTCCACGCCGT AAACGATGAGTGCTAAGTGTTAGAGGGTTTCCGCC CTTTAGTGCTGAAGTTAACGCATTAAGCACTCCGC CTGGAGACGCCGAACGTG, respectively.

A comprehensive analysis of 16S rRNA Bacillus gene tree was conducted in order to clarify the relationship between DL3 and DL4 isolates and closely related Bacillus species. The $16 \mathrm{~S}$ rRNA gene sequence of the isolatesDL3 and DL4was compared to the nucleotide sequences of other Bacillus strains at the NCBI GenBank database. The hylogenetic tree was generated based on the comparison between 16S rRNA gene sequence of the isolatesDL3 and DL4 and other 490 and 489 nucleotide sequences from closely related Bacillus strains using neighbor-joining method. NJ phylogenetic tree was divided into two large clades. Isolates DL3 and DL4 were

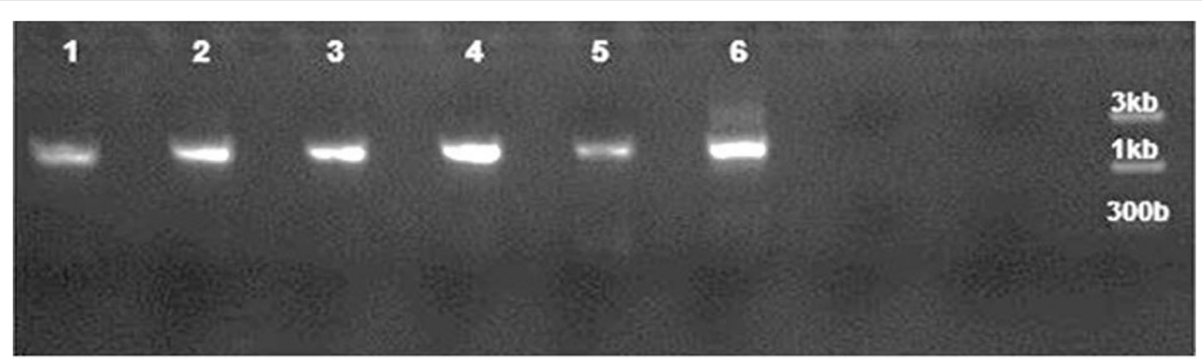

Fig. 1 Gel electrophoresis of agarose gel illustrating the amplification of partial 16S rRNA genes of isolates DL3 and DL4 (lanes 3 and 4, respectively) 


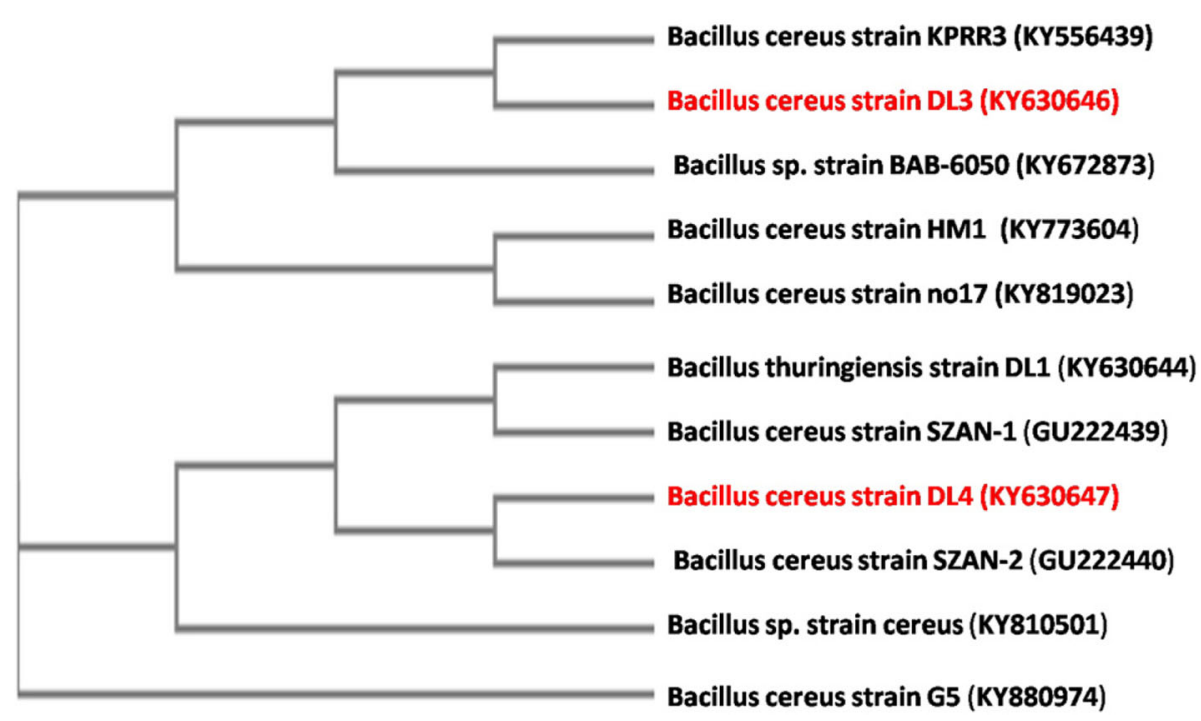

Fig. 2 Phylogenetic tree based on 16S rRNA gene sequences of strains (DL3, DL4) and other Bacillus species

grouped with Bacillus cereus strain SZAN-2 (GU222440) and Bacillus cereus strain KPRR3 (KY556439), respectively, as shown in (Fig. 2). It is of interest to notice that $490 \mathrm{bp}$ of the DL3 and DL4 sequences below were highly aligned (100\%) when they were tested according to BLASTn, nucleotide alignment (bl2seq). This 100\% identity shows that PCR product was almost fully sequenced. Based on the analysis of the 16S rRNA gene sequence, the bacteria isolated from dead/diseased desert locust were identified as Bacillus cereus strain DL3 and Bacillus cereus strain DL4.

B. cereus strain WGPSB-2 was reported to cause 92 and $67 \%$ mortality in grubs of $A$. dimidiate and $H$. seticollis, respectively (Selvakumar et al. 2007 and Sushil et al. 2008). The insecticidal property of $B$. cereus has been attributed to the production of the lipase toxin phospholipase C (Lysenko 1972a, 1972b) and the paralytic toxin sphingomyelinase C (Nishiwaki et al. 2004). A complete mortality $(100 \%)$ occurred to desert locust when subjected to a cell density of $539 \times 10^{6}$ DL3 and $23 \times 10^{6}$ DL4 after $48 \mathrm{~h}$ and 3 days, respectively. The body color of locust converted throughout the lethal treatment with antagonistic bacterial isolates from red to dark red and finally black when decomposed. B. cereus has the ability of producing enteric toxins that have agronomically useful traits such as antibiotic production.

\section{Conclusions}

Two Bacillus cereus isolated from infected desert nymphs in Egypt have the potential to be very efficient if they were formulated as biopesticide formulation and be part of the integrated locust management system to decrease the quantities of chemical synthetic pesticides usually used for this target.
Our bacteria were successfully isolated and identified to the species level, but further research needs to be done to confirm the strains level and to characterize the type of toxin excrete for each isolate and involved in causing sepsis in desert locust nymphs.

\section{Acknowledgements}

The authors wish to express their deep appreciation and gratitude to Dr. Ashraf Marzouk, Microbiology technician of Microbiological Resources Center (MIRCEN), Faculty of Agriculture, Ain Shams University, for helping in the laboratory experiment.

Availability of data and materials

The authors declare that they have no objection to the availability of data and materials.

\section{Authors' contributions}

MR and TAM carried out the microbiology stuff such as isolation of the entomopathogenic bacteria from the dead/infected locusts, bacterial purification, and then preparation of the bacterial suspension in order to bioassay them. Also, they carried out the molecular identification of the promised isolates. MESEZ carried out the experimental design and revised the final manuscript. AA participated in the sequence alignment. GMA participated with MR and TAM in the bioassay trials and statistical analysis and then drafted the manuscript. All authors read and approved the final manuscript.

\section{Ethics approval}

Not applicable.

\section{Competing interests}

The authors declare that they have no competing interests.

\section{Publisher's Note}

Springer Nature remains neutral with regard to jurisdictional claims in published maps and institutional affiliations.

\section{Author details}

'Department of Locust and Grasshoppers Research, Plant Protection Research Institute, Agricultural Research Center, Dokki, Giza, Cairo 12311, Egypt. ${ }^{2}$ Department of Plant Protection, Faculty of Agriculture, Ain Shams University, Cairo, Egypt. ${ }^{3}$ Department of Food Science, Faculty of Agriculture, Ain Shams University, Cairo, Egypt. 
Received: 29 July 2017 Accepted: 28 May 2018

Published online: 12 June 2018

\section{References}

Altschul SF, Gish W, Miller W, Myers EW, Lipman DJ (1990) Basic local alignment search tool. J Mol Biol 215:729-731

Bacon CW, Hinton DM (2002) Endophytic and biological control potential of Bacillus mojavensis and related species. J Biol Control 23:274-284

Clarridge JE (2004) Impact of 165 rRNA gene sequence analysis for identification of bacteria on clinical microbiology and infectious diseases. Clin Microbiol Rev 17(4):840-862

Goettel MS, Jaronski ST (1997) Safety and registration of microbial control agents of grasshoppers and locusts. Mem Entomol Soc Can 171:83-99

Guttmann DM, Ellar DJ (2000) Phenotypic and genotypic comparisons of 23 strains from the $B$. cereus complex for a selection of known and putative $B$. thuringiensis virulence factors. FEMS Microbiol Lett 188:7-13

Johnson DL (1997) Nosematidae and other Protozoa as agents for control of grasshoppers and locusts: current status and prospects. Mem. Entomol. Soc. Can. 171:375-389

Lecoq M (2001) Recent progress in Desert and Migratory Locust management in Africa. Are preventive actions possible? J of Orthoptera Res 10:277-291

Lomer CJ, Batemman RP, Johnson DL, Langewald J, Thomas M (2001) Biological control of locusts and grasshoppers. Ann Rev of Entomol 46:667-702

Lysenko O (1972a) Pathogenicity of Bacillus cereus for insects. I. Production of phospholipase C. Folia Microbiol 17:221-227

Lysenko O (1972b) Pathogenicity of Bacillus cereus for insects. II. Toxicity of phospholipase C for Galleria mellonella. Folia Microbiol 17:228-231

Mashtoly TA, Abolmaaty A, Thompson N, El-Zemaity MS, Hussien MI, Alm SR (2010) Enhanced toxicity of Bacillus thuringiensis japonensis strain Buibui, toxin to oriental beetle and northern masked chafer (Coleoptera: Scarabaeidae) larvae with Bacillussp. nfd2. J Econ Entomol 103(5):1444-1454

Mashtoly TA, Abolmaaty A, Thompson N, El-Zemaity MS, Hussien MI, Alm SR (2011) Enhanced toxicity of Bacillus thuringiensis subspecies kurstaki and aizawai to black cutworm larvae (Lepidoptera: Noctuidae) with Bacillus sp. NFD2 and Pseudomonas sp. FNFD1. J Econ Entomol 104(1):41-46

Nishiwaki H, Ito K, Otsuki K, Yamamoto H, Komai K (2004) Purification and functional characterization of insecticidal sphingomyelinase $\mathrm{C}$ produced by Bacillus cereus. Eur J Biochem 271:601-606

Provost F, Laurent F, Camacho uzcategui LR, Boiron P (1997) Molecular study of persistence of Nocardiaasteroides and Nocardiaotitidiscaviarum strains in patients with long-term nocardiosis. J Clin Microbiol 35:1157-1160

Selvakumar G, Mohan M, Sushil SN, Kundu S, Bhatt JC, Gupta HS (2007) Characterization and phylogenetic analysis of an entomopathogenic Bacillus cereus strain WGPSB-2 (MTCC7182) isolated from white grub Anomala dimidiata (Coleoptera: Scarabaeidae). Biocontrol Sci Tech 17:525-534

Sezen K, Demir l, Demirba Z (2005) Investigations on bacteria as a potential biological control agent of summer chafer, Amphimallon solstitialis L. (Coleoptera: Scarabaeidae). J Microbiol 43:463-468

Spadaro D, Gullino ML (2004) State of the art and future prospects of the biological control of postharvest fruit diseases. Int J Food Microbiol 91:185194

Sun YP (1950) Toxicity index - an improved method of comparing the relative toxicity of insecticides. J Econ Entomol 43:45-53

Sushil SN, Mohan M, Selvakumar G, Bhatt JC, Gupta HS (2008) Isolation and toxicity evaluation of bacterial entomopathogens against phytophagous white grubs (Coleoptera: Scarabaeidae) in Indian Himalayan hills. Int J Pest Manag 54(4):301-307

Thompson LT, Moyer RJ Jr, Akase E, Disterhoft JF (1994) A system for quantitative analysis of associative learning. Part 1. Hardware interfaces with cross-species applications. J Neurosci Methods 54:109-117

Woese CR, Stackebrandt ET, Macke J, Fox GE (1985) A phylogenetic definition of the major eubacterial taxa. Syst Appl Microbiol 6:143-151

\section{Submit your manuscript to a SpringerOpen ${ }^{\circ}$ journal and benefit from:}

- Convenient online submission

- Rigorous peer review

- Open access: articles freely available online

- High visibility within the field

- Retaining the copyright to your article

Submit your next manuscript at $\boldsymbol{\nabla}$ springeropen.com 